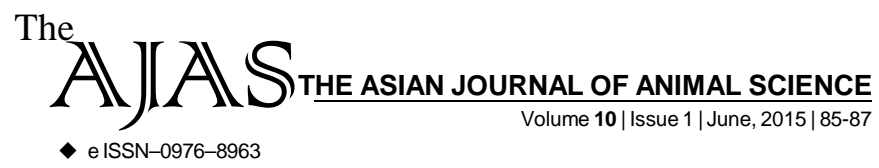

\title{
Constraints encountered in the buffalo rearing by the farmers in breeding tract of Nili-Ravi
}

MUNISH KUMAR

AUTHOR FOR CORRESPONDING :

\section{MUNISH KUMAR}

Krishi Vigyan Kendra, FARIDKOT

(PUNJAB) INDIA

Email: dr_vodehra@yahoo.com

\begin{abstract}
Nili-Ravi breed of buffalo is one of the best buffalo breed of the world. The present study was conducted in the breeding tract of Nili-Ravi breed of buffalo for understanding the problems faced by the buffalo keepers. It was found during the study that the main breeding constraint among majority (93.75\%) of respondents was their preference towards natural service as compared to artificial insemination. Other important breeding constraint experienced by 77.5 per cent of the respondents was the non-availability of good Nili-Ravi buffalo bulls. So the farmers had to breed their Nili-Ravi buffaloes with the available bulls of other breeds such as Murrah. Majority (73.75\%) of farmers were not having any knowledge about the breeds of buffaloes. Lack of knowledge about balanced feeding and high cost of concentrates were two main constraints about the feeding management faced by 83.75 and 76.25 per cent of respondents, respectively. Nearly 53 per cent respondents reported the problem of lack of finance for the construction of animal houses. In 45 per cent of the cases, farmer's ignorance towards animal housing was a major problem as far as housing practice was concerned.
\end{abstract}

KEY WORDS...... Buffalo, Management, Constraints, Nili-Ravi

HOW TO CITE THIS ARTICLE - Kumar, Munish (2015). Constraints encountered in the buffalo rearing by the farmers in breeding tract of Nili-Ravi. Asian J. Animal Sci., 10(1) : 85-87.

ARTICLE CHRONICLE - Received : 06.01.2015; Accepted : 30.05.2015 